\title{
Trust and expectation on psychiatrist and its correlation with satisfaction and adherence in patients with mental illness
}

\author{
Dushad RAm ${ }^{1}$, BaSavana GowdaPpa ${ }^{1}$ \\ ${ }_{1}^{1}$ Department of Psychiatry, JSS Medical College and Hospital, MG Road Agrahara, Mysore.
}

Received: 9/3/2014 - Accepted: 2/20/2015

DOI: 10.1590/0101-60830000000040

\begin{abstract}
Background: Trust and expectation are important aspect of doctor patient relationship and its role in patient's satisfaction and medication adherence is unclear. Objective: To study the levels of trust and expectation on psychiatrist and its relationship with patient's satisfaction and treatment adherence. Methods: One hundred and twenty three consecutive outpatients were recruited on follow-up if they satisfied the selection criteria. They were assessed with socio-demographic and clinical proforma designed for this study, Patient Trust Scale, Patient Satisfaction Survey, Patient Expectations Questionnaire and Medication Adherence Rating Scale. Results: There was a high mean score on trust scale (Mean 38.9, SD 8.5) and expectation questionnaire (Mean 13.5, SD 3.3). On Kruskal-Wallis $\mathrm{H}$ test significant group differences were observed in nuclear vs joint family type $\left(\chi^{2}=18.496, \eta^{2}=.151, \mathrm{df}=1\right.$, Sig. $\left.=.000\right)$ and knowledge of treatment option (medication only vs medication + psychotherapy) treatment option $\left(\chi^{2}=18.100, \eta^{2}=.148, \mathrm{df}=2\right.$, Sig. $\left.=.000\right)$ and occupational status (employed vs unemployed) $\left(\chi^{2}=3.165, \eta^{2}=.029, \mathrm{df}=1\right.$, Sig. $\left.=.056\right)$ on the score of PTS. Similar differences were also observed in method of treatment sought before (no treatment vs allopathic) $\left(\chi^{2}=.065, \eta^{2}=.065, \mathrm{df}=3\right.$, Sig. $\left.=.005\right)$, knowledge about treatment option (medication only vs medication + psychotherapy) $\left(\chi^{2}=\right.$ $.026, \eta^{2}=.161, \mathrm{df}=2$, Sig. $\left.=.000\right)$ and occupation (employed vs unemployed) $\left(\chi^{2}=.061, \eta^{2}=.061, \mathrm{df}=1\right.$, Sig. $\left.=.006\right)$ on the score of PEQ. On regression analysis $\left(\mathrm{R}^{2}=.723, \mathrm{~F}=156.46, \mathrm{p}=.000\right)$ value of the score on patient satisfaction was statistically significant as predicted by score on measure of expectation (beta $=-0.095, \mathrm{t}=-1.966, \mathrm{p}=0.052)$ and trust (beta $=.842, \mathrm{t}=17.504, \mathrm{p}=.000$ ). Discussion: Levels of patients trust and expectation on physician varies with knowledge about treatment option \& occupational status, and significantly associated with levels of satisfaction.
\end{abstract}

Ram D, Gowdappa B / Arch Clin Psychiatry. 2015;42(1):13-7

Keywords: Patient trust, patient expectation, patient satisfaction, medication adherence, mental illness.

\section{Introduction}

Patient expectations of therapeutic benefit are crucial in treatment outcomes \& satisfaction, and are shaped by characteristics of patient and disease $\mathrm{e}^{1-4}$. Few decades ago patients generally had an expectation of symptom reduction. It is changing over time due to advancements in treatment, growing awareness of mental health, reduced stigma and increasing consumerism ${ }^{5}$. Patient's trust is crucial in doctor patient relationship. It is often influenced by general perception of the community about a physician's reputation ${ }^{6}$. The trust that the physician will perform a particular action important to the patient, may mediate the effectiveness of medical care and satisfaction ${ }^{6,7}$. Though there has been a fair level of trust in physicians in the past, it is changing over time due to the reports of high profile physician fraud, drug pushing, malfeasance and malpractice ${ }^{7,8}$.

Treatment satisfaction is not an all or none phenomena. It varies with treatment response, demographic feature, cultural background, previous treatment experience and quality of services/care ${ }^{9-11}$. Similarly, the degree of medication adherence varies with the demographic characteristics of the patients, psychopathology, associated disability and supervision ${ }^{12-14}$. Role of patient's expectation and trust on physician in mediating treatment satisfaction and adherence is unclear. This study was carried out with the hypothesis that: 1) The levels of patients' trust and expectation varies with demographic and clinical variables; 2) The levels of patients' trust and expectation varies with the levels of the patients' satisfaction and medication adherence.

\section{Methods}

This study was conducted among patients with mental illness in remission, who were living in the community and attending outpatient department of psychiatry for follow-up at a tertiary care centre in south India. Out of 140 consecutive patients screened over a period of three months; 123 met study selection criteria and were recruited in this study after obtaining an informed consent.
The inclusion criteria were outpatient males and females, an ICD 10 diagnosis of axis I psychiatric disorder currently in remission as per treating psychiatrist, aged $14-65$ years and $\geq 2$ consultation visit. Patients were excluded if they had a co-morbid chronic physical illness, diagnosis of unexplained physical complaint, involvement (self or any family member) in delivering faith or other type of healing practices and an ICD 10 diagnosis of mental retardation or dementia. They were assessed with socio-demographic and clinical proforma designed for this study. Patient Trust Scale (PTS) was used to assess the level of patients' trust on the psychiatrist ${ }^{15}$. This scale has excellent internal reliability (Cronbach alpha $=0.94)$ and contains 10 items to assess the domains of privacy, information related to illness, investigation or optimal care and treatment cost. To evaluate expectation, the Patient Expectations Questionnaire (PEQ) was used. This scale scored alpha $=0.82$ on measure of reliability and assess patients upbringing, opinion about the cause, physical illness, emotional problem, current relationship, confidentiality, ongoing treatment, consulting family physician, medication to be given and best treatment plans ${ }^{16}$.

To determine satisfaction, the Patient Satisfaction Survey (PSS) was used. This nine items tool includes waiting time for appointment and office visit, convenience of office location, contact over the phone, time spent with the physician, physicians' skill attitude \& explanation, and overall satisfaction ${ }^{17}$. All item has 5 point rating, ranging from poor to excellent. This tool is patient friendly; and has been used to examine patient satisfaction in studies. This instrument (also known as visit-specific satisfaction questionnaire) has established psychometric properties that demonstrate reliability and validity; internal consistency reliability estimates ranged from 0.87 to 0.93 based on Cronback's $\alpha$.

Medication Adherence Rating Scale (MARS) was used to estimate the level of medication adherence ${ }^{18}$. This tool assessed medication intake behaviour in terms of sincerity, effect of continuing or stopping medication, perception of self control etc. This scale is commonly used and has a good internal reliability (Cronbach $\alpha=0.73$ ). 
The data were analysed using SPSS Version 16. Descriptive statistics were used to express demographic and clinical characteristic. The distribution of the sample was assessed with the Kolmogorov-Smirnov and Shapiro-Wilk test and found to be significantly skewed. Since analysis required comparison of more than two variables, Kruskal-Wallis $\mathrm{H}$ test was used to know the group difference of demographic and clinical variables on the score of different scales and a post hoc analysis was done (for comparison of $\geq$ 3 groups). A regression analysis was conducted to know if patients score on measure of trust and expectation can predict the values of scores on measure of satisfaction and medication adherence. The level of statistical significance was kept at $\mathrm{p}<0.05$ for all tests.

\section{Results}

The majority of the patients were married, Hindu, from the nuclear family, consulting a single psychiatrist regularly; ongoing treatment was the first psychiatric intervention and felt to refer other patient to the psychiatrist (Table 1). Table 2 reveals scores on the PTS (Mean 38.9, SD \pm 8.53 ), PSS (Mean 32.5, SD \pm 8.0 ), MARS (Mean 16.0, SD \pm 2.2 ) and PEQ (Mean 13.5, $\mathrm{SD} \pm 3.3$ ).

Table 1. Sociodemographic and clinical characteristics

\begin{tabular}{|c|c|c|}
\hline Variables & $n$ & $\%$ \\
\hline \multicolumn{3}{|l|}{ Gender } \\
\hline Male & 61 & 49.6 \\
\hline Female & 62 & 50.4 \\
\hline \multicolumn{3}{|l|}{ Occupation } \\
\hline Unemployed & 57 & 46.3 \\
\hline Self-employed & 39 & 31.7 \\
\hline Employed & 27 & 22.0 \\
\hline \multicolumn{3}{|l|}{ Socioeconomic status } \\
\hline Low & 54 & 43.9 \\
\hline Middle & 68 & 55.3 \\
\hline High & 1 & 0.8 \\
\hline Variables & Mean & Std. deviation \\
\hline \multicolumn{3}{|l|}{ Religion } \\
\hline Hindu & 110 & 89.4 \\
\hline Muslim & 13 & 10.6 \\
\hline \multicolumn{3}{|l|}{ Marital status } \\
\hline Single & 29 & 23.6 \\
\hline Married & 93 & 75.6 \\
\hline Other & 1 & 0.8 \\
\hline \multicolumn{3}{|l|}{ Domicile } \\
\hline Rural & 67 & 54.5 \\
\hline Urban & 56 & 45.5 \\
\hline \multicolumn{3}{|l|}{ Family type } \\
\hline Nuclear & 75 & 61.0 \\
\hline Joint & 47 & 38.2 \\
\hline Other & 1 & 0.8 \\
\hline \multicolumn{3}{|c|}{ Consulting single psychiatrist } \\
\hline Yes & 110 & 89.4 \\
\hline No & 13 & 10.6 \\
\hline \multicolumn{3}{|l|}{ First referral by } \\
\hline Self & 47 & 38.2 \\
\hline Family & 58 & 47.2 \\
\hline Society & 5 & 4.1 \\
\hline Health professionals & 13 & 10.6 \\
\hline \multicolumn{3}{|l|}{ Regularity of follow-up } \\
\hline Always & 80 & 65.0 \\
\hline Mostly & 31 & 25.2 \\
\hline Half the time & 10 & 8.1 \\
\hline Some time & 2 & 1.6 \\
\hline
\end{tabular}

\begin{tabular}{|l|c|c|}
\hline Variables & Mean & Std. deviation \\
\hline Diagnosis & & \\
\hline F 10 & 11 & 8.9 \\
\hline F20 & 9 & 7.3 \\
\hline F 30 & 85 & 69.1 \\
\hline F 40 & 16 & 13.0 \\
\hline Other & 2 & 1.6 \\
\hline Treatment sought before & & \\
\hline No treatment & 100 & 81.3 \\
\hline Magico-religious & 3 & 2.4 \\
\hline Allopathic & 17 & 13.8 \\
\hline Ayurvedic & 3 & 2.4 \\
\hline Option about treatment decision & & \\
\hline Doctor should decide & 75 & 61.0 \\
\hline I should decide & 5 & 4.1 \\
\hline Both should decide & 39 & 31.7 \\
\hline Any of these & 4 & 3.3 \\
\hline Referring others to his physician & & \\
\hline Yes & 118 & 95.9 \\
\hline No & 5 & 4.1 \\
\hline Knowledge about treatment option & & \\
\hline Medication only & 4 & 55.3 \\
\hline Psychotherapy only & 51 & 41.5 \\
\hline Medication + psychotherapy & & \\
\hline
\end{tabular}

Table 2. Sociodemographic and clinical characteristics

\begin{tabular}{|l|c|c|}
\hline Variables & Mean & Std. deviation \\
\hline Age & 37.12 & 12.74 \\
\hline Education & 5.69 & 5.23 \\
\hline Age at onset & 32.20 & 12.58 \\
\hline Total duration of illness & 4.59 & 5.14 \\
\hline Duration of consultation & 2.19 & 2.34 \\
\hline Score on Patient Trust Scale & 38.98 & 8.53 \\
\hline Score on Patient Satisfaction Survey & 32.52 & 8.05 \\
\hline Score on Medication Adherence Rating Scale & 16.04 & 2.26 \\
\hline Score on Patient Expectations Questionnaire & 13.57 & 3.30 \\
\hline
\end{tabular}

On Kruskal-Wallis $\mathrm{H}$ test significant group differences were observed in nuclear vs joint family type $\left(\chi^{2}=18.496, \eta^{2}=.151\right.$, df $=1$, Sig. $=.000$ ), knowledge of treatment option (medication only vs medication + psychotherapy $)\left(\chi^{2}=18.100, \eta^{2}=.148, \mathrm{df}=2\right.$, Sig. $=.000)$ and occupational status (employed vs unemployed) $\left(\chi^{2}=\right.$ $3.165, \eta^{2}=.029, \mathrm{df}=1$, Sig. $\left.=.056\right)$ on the score of PTS. Similar differences were also observed in method of treatment sought before (no treatment vs allopathic) $\left(\chi^{2}=.065, \eta^{2}=.065, \mathrm{df}=3\right.$, Sig. $\left.=.005\right)$, knowledge about treatment option (medication only vs medication + psychotherapy) $\left(\chi^{2}=.026, \eta^{2}=.161, \mathrm{df}=2\right.$, Sig. $\left.=.000\right)$ and occupation (employed vs unemployed) $\left(\chi^{2}=.061, \eta^{2}=.061, \mathrm{df}=1\right.$, Sig. $=.006)$ on the score of PEQ (Tables 3 and 4$)$.

Regression analysis was done to know if the score on measure of patient expectation and trust can predict the value of score on patient satisfaction $\left(\mathrm{R}^{2}=.723, \mathrm{~F}=156.46, \mathrm{p}=.000\right)$. Score on patient expectation (beta $=-0.095, \mathrm{t}=-1.966, \mathrm{p}=0.052)$ and trust (beta $=$ $.842, \mathrm{t}=17.504, \mathrm{p}=.000)$ significantly predicted the value of score on patient satisfaction. A regression analysis was also done to know if the score on measure of patient trust and expectation can predict the value of the score on patient medication adherence $\left(\mathrm{R}^{2}=.26, \mathrm{~F}=\right.$ $1.629, \mathrm{p}=.200)$. Both did not predict significantly the value of score on the medication adherence (Table 5). 
Table 3. Kruskal Wallis H Test for group comparison of demographic variables on score of PTS \& PEO

\begin{tabular}{|c|c|c|c|c|c|c|c|c|}
\hline & & Group & $\mathrm{N}$ & Mean Rank & $\chi^{2}$ & $\eta^{2}$ & df & Asymp. Sig \\
\hline \multirow[t]{2}{*}{ PTS Total* Occupation } & & Unemployed & 57 & 68.61 & 3.658 & .029 & 1 & .056 \\
\hline & & Employed & 66 & 56.30 & & & & \\
\hline \multirow[t]{2}{*}{ PTS Total* Family type } & & Nuclear & 76 & 51.14 & 18.496 & .151 & 1 & .000 \\
\hline & & Joint & 47 & 79.55 & & & & \\
\hline \multirow[t]{6}{*}{ PTS Total ${ }^{*}$ Knowledge of treatment } & 1 & Medication only & 68 & 36.26 & .155 & .002 & 1 & .694 \\
\hline & & Psychotherapy only & 4 & 40.50 & & & & \\
\hline & 2 & Psychotherapy only & 4 & 13.88 & 3.380 & .062 & 1 & .066 \\
\hline & & Medication + psychotherapy & 51 & 29.11 & & & & \\
\hline & 3 & Medication only & 68 & 48.37 & 18.100 & .153 & 1 & .000 \\
\hline & & Medication + psychotherapy & 51 & 75.51 & & & & \\
\hline \multirow[t]{2}{*}{ PEQ Total* Occupation } & & Unemployed & 57 & 52.80 & 7.474 & .061 & 1 & .006 \\
\hline & & Employed & 66 & 69.95 & & & & \\
\hline \multirow[t]{12}{*}{ PEO Total* Treatment sought before } & 1 & No treatment & 100 & 52.52 & 1.118 & .010 & 1 & .290 \\
\hline & & Magicoreligious & 3 & 34.50 & & & & \\
\hline & 2 & Magicoreligious & 3 & 4.83 & 3.516 & .185 & 1 & .061 \\
\hline & & Allopathic & 17 & 11.50 & & & & \\
\hline & 3 & Allopathic & 17 & 11.03 & .977 & .051 & 1 & .323 \\
\hline & & Ayurvedic & 3 & 7.50 & & & & \\
\hline & 4 & No treatment & 100 & 55.44 & 8.029 & .069 & 1 & .005 \\
\hline & & Allopathic & 17 & 79.94 & & & & \\
\hline & 5 & No treatment & 100 & 51.89 & .049 & .000 & 1 & .825 \\
\hline & & Ayurvedic & 3 & 55.67 & & & & \\
\hline & 6 & Magicoreligious & 3 & 2.83 & .784 & .156 & 1 & .376 \\
\hline & & Ayurvedic & 3 & 4.17 & & & & \\
\hline \multirow[t]{6}{*}{ PEO Total ${ }^{*}$ Knowledge of treatment } & 1 & Medication only & 68 & 35.60 & 2.454 & .034 & 1 & .117 \\
\hline & & Psychotherapy only & 4 & 51.75 & & & & \\
\hline & 2 & Psychotherapy only & 4 & 49.88 & 8.442 & 0.153 & 1 & .004 \\
\hline & & Medication + psychotherapy & 51 & 26.28 & & & & \\
\hline & 3 & Medication only & 68 & 75.01 & 31.779 & .267 & 1 & .000 \\
\hline & & Medication + psychotherapy & 51 & 39.98 & & & & \\
\hline
\end{tabular}

Table 4. Relationship of expectation \& trust with satisfaction

\begin{tabular}{|l|c|c|c|c|c|c|}
\hline \multirow{2}{*}{ Model } & \multirow{2}{*}{ Predictor } & \multicolumn{2}{|c|}{$\begin{array}{c}\text { Unstandardized } \\
\text { Coefficients }\end{array}$} & $\begin{array}{c}\text { Standardized } \\
\text { Coefficients }\end{array}$ & \multirow{2}{*}{$\mathrm{t}$} & \multirow{2}{*}{ Sig. } \\
\cline { 3 - 5 } & & $\mathrm{B}$ & Std. Error & Beta & & \\
\hline 1 & (Constant) & 4.698 & 2.449 & & 1.919 & .057 \\
\hline & PE0 Total & -.230 & .117 & -.095 & -1.966 & .052 \\
\hline & PTS Total & .794 & .045 & .842 & 17.504 & .000 \\
\hline
\end{tabular}

Dependent variable: PSS total

$R^{2}=.723, F=156.46, p=.000$

Table 5. Relationship of expectation \& trust with adherence

\begin{tabular}{|l|c|c|c|c|c|c|}
\hline \multirow{2}{*}{ Model } & \multirow{2}{*}{ Predictor } & \multicolumn{2}{|c|}{$\begin{array}{c}\text { Unstandardized } \\
\text { Coefficients }\end{array}$} & $\begin{array}{c}\text { Standardized } \\
\text { Coefficients }\end{array}$ & \multirow{2}{*}{$\mathrm{t}$} & \multirow{2}{*}{ Sig. } \\
\cline { 3 - 5 } & & $\mathrm{B}$ & Std. Error & Beta & & \\
\hline 1 & (Constant) & 17.186 & 1.291 & & 13.316 & .000 \\
\hline & PTS Total & .009 & .024 & .032 & .360 & .719 \\
\hline & PE0 Total & -.108 & .062 & -.158 & -1.756 & .082 \\
\hline
\end{tabular}

Dependent variable: MARS total.

$\mathrm{R}^{2}=.26, \mathrm{~F}=1.629, \mathrm{p}=.200$

\section{Discussion}

In this study, patients with an ICD 10 diagnosis of axis I psychiatric disorder in remission were included because psychopathology may interfere with the perception of trust and expectation. Similarly patients involved in faith healing were excluded as they are known to have more faith in their model of illness that can influence the trust and expectation. Believe model of physical illness (depending upon severity of symptoms, duration, distress, disability etc.) may influence the expectation and an ICD 10 diagnosis of mental retardation or dementia may give rise to the reliability issue, hence they were excluded from this study.

\section{Socio-demographic characteristics}

More patients were Hindu who did not receive any treatment before, currently consulting a single psychiatrist regularly, and felt to refer the other patients to psychiatrists. Such observation was likely as this study was conducted at a place where a majority of the population were Hindus, with few available mental health professionals.

We also observed a high mean score on the PTS, PEQ, PSS, and MARS. High trust level probably reflects the prevailed paternalistic model of doctor patient relationships in India. In most part of India the doctors are traditionally believed to be honest, harmless to their patients, save human life, and can cure all types of illness. High level of satisfaction and adherence observed in this study was possibly the result of improvement and limited availability of alternative mental health care service.

\section{Relationship of socio-demographic and clinical variables with expectation and trust}

On the score of PTS there was a statistically significant group difference in family types (joint vs nuclear) and patient's knowledge about treatment options (medication only vs medication + psychotherapy). Patients with a joint family are more likely to have social or general 
trust, while those with a nuclear family are more likely to have interpersonal trust ${ }^{19}$. Similarly, a trust may vary with knowledge about treatment options (and health literacy and orientation of illness model). The knowledge and appreciation of psychological treatment may mediate the trust on a qualified mental health professional who are more likely to address an illness on the basis of the biopsychosocial model. Those with knowledge of only pharmacotherapy may be medical model oriented and rely more on role of medication ${ }^{20}$.

On the score of the expectation measure there was a statistically significant group difference in employment status (employed vs unemployed), knowledge of different treatment options (medication only vs medication + psychotherapy) and methods of treatment sought before (no treatment vs allopathic). The unemployed patients may expect less treatment cost, while employed status demands more confidentiality \& best treatment in order to meet work demands. Patients background may influence their expectation. Expectation of subject without previous treatment, may depends upon their orientation of illness model. Those who are oriented to the medical model may expect more probing on illness related issues or appropriate medication, while bio-psychosocial model oriented patient may expect their physician to address the psychosocial aspects of illness ${ }^{20,21}$. During the initial consultation, the patient may expect remission of symptoms or reduction of distress, while those who already received pharmacotherapy (allopathic) may expect issues that were unsuccessfully addressed by the previous health care provider. In the same manner the knowledge of treatment option may also influence patient expectation.

\section{Relationship of patient's expectation and trust with satisfaction and adherence}

Score on the measure of patient's expectation significantly predicted the value of patient satisfaction. However, the negative beta value indicates that, if the expectation is more than satisfaction will be low. Many views have been put forward for such observation. A few decades ago higher satisfaction was thought to be due to the congruence of patient orientations and provision of health services, positive personal beliefs and values of care, personal preferences and good interpersonal process of care ${ }^{22-25}$. Over time, multiple factors appeared to mediate the satisfaction such as patients' demographic characteristics, personal experience, past experience, media, information provided by treatment provider and experiences from friends or relatives that have utilised similar health care service ${ }^{26,27}$. Inappropriately high expectations may cause dissatisfaction with optimal healthcare while inappropriately low expectations may be satisfied with deficient health care. Though in multi-culture society accurate assessment of patient expectation is often difficult, the presence of a realistic expectation is associated with adequate satisfaction ${ }^{28}$. An expectation is realistic when they correspond to known evidence of probabilities of outcome for a person's health profile. This finding may have implication, since most health care providers are now focusing more on patient satisfaction. Adequate information about patient health status, available treatment option and limitation in current understanding \& treatment may help the patients have a realistic expectation toward the physician.

In this study score on the measure of patient's trust significantly predicted the value of patient satisfaction. Generally Indian patients have a high level of trust in physician ${ }^{7}$. There is a prevalent Indian traditional belief that physicians are morally superior and do the best to save the patient's life. In contrast, in western countries the trust develops when patients perceive their physician to be sincere, credible, honest, and benevolent ${ }^{29,30}$. The high level of trust can result in a high response rate (placebo response) and vice versa ${ }^{31}$. When trust is high, little response may induce more satisfaction. Since all patients in this study were improved with the treatment, satisfaction appeared to be obvious ${ }^{13,24}$.

Patient score on the measure of trust and expectation did not predict the value of score on medication adherence. Trust is more likely to mediate the treatment seeking behaviour, while a subsequent continuation of adherence behaviour depends upon patient evaluation of service and experience of improvement ${ }^{32}$. Adherence requires self-determination and continuous effort that develops after evaluation of needs, symptom severity and improvement with medication ${ }^{33,34}$. The common cause of non-adherence among Indians includes the absence of symptoms, transportation problems, drug side effects, culture myth, social factors, economic factors, knowledge \& insight and misconception about the treatment and illness ${ }^{35}$.

Though our hypothesis appeared to be partially true, finding of this study should be interpreted in the background of the limitations of this study. Patient were recruited by consecutive method at tertiary care centre, result may not be applicable to psychiatric patients in the general population. Though the sample characteristics were similar to other studies conducted in India ${ }^{36,37}$, the sample size was small, sample composed predominantly of mood disorders patients, study design was cross sectional without control and no assessment of knowledge about illness (especially biomedical model). Further study is needed with addressing limitation of this study.

\section{Conflict of interest}

Nil.

\section{Acknowledgement}

Author thanks staff of department of psychiatry for their moral support.

\section{References}

1. Crow R, Gage H, Hampson S, Hart J, Kimber A, Thomas H. The role of expectancies in the placebo effect and their use in the delivery of health care: a systematic review. Health Technol Assess. 1999;3:1-96.

2. Constantino MJ, Arnkoff DB, Glass CR, Ametrano RM, Smith JZ. Expectations. J Clin Psychol. 2011;67:184-92.

3. van Hartingsveld F, Ostelo RWJG, Cuijpers P, de Vos R, Riphagen II, de Vet HCW. Treatment-related and patient-related expectations of patients with musculoskeletal disorders: a systematic review of published measurement tools. Clin J Pain. 2010;26:470-88.

4. Noble PC, Conditt MA, Cook KF, Mathis KB. The John Insall Award Patient expectations affect satisfaction with total knee arthroplasty. Clin Orthop Relat Res. 2006;452:35-43.

5. Bowling A, Rowe G, Lambert N, Waddington M, Mahtani KR, Kenten C et al. The measurement of patients' expectations for health care: a review and psychometric testing of a measure of patients' expectations. Health Technol Assess. 2012;16(30):1-509.

6. Hall MA, Dugan E, Zheng B, Mishra AK. Trust in physicians and medical institutions: what is it, can it be measured, and does it matter? The Milbank Quarterly. 2001;79(4):613-39.

7. Baidya M, Gopichandran V, Kosalram K. Patient-physician trust among adults of rural Tamil Nadu: a community-based survey. J Postgrad Med. 2014;60:21-6.

8. Mainous AG, Kerse N, Brock CD, Hughes K, Pruitt C. Doctors developing patient trust: perspectives from the United States and New Zealand. N Z Fam Physician. 2003;30(5):336-41.

9. Himmel W, Lippert-Urbanke E, Kochen MM. Are patients more satisfied when they receive a prescription? The effect of patient expectations in general practice. Scand J Prim Health Care. 1997;15:118-22.

10. Baker R, Streatfield J. What type of general practice do patients prefer? Exploration of practice characteristics influencing patient satisfaction. Br J Gen Pract. 1995;45:654-59.

11. Baker R. Characteristics of practices, general-practitioners and patients related to levels of patients' satisfaction with consultations. $\mathrm{Br}$ J Gen Pract. 1996;46:601-5.

12. Sabaté E. WHO Adherence Meeting Report. Geneva, World Health Organization; 2001.

13. Griffith $S$. A review of the factors associated with patient compliance and the taking of prescribed medicines. Br J Gen Pract. 1990;40(332):114-6. 
14. Morris LS, Schulz RM. Patient compliance: an overview. J Clin Pharm Ther. 1992;17:183-95.

15. Kao AC, Green DC, Davis NA, Koplan JP, Cleary PD. Patient's trust in their physicians: effects of choice, continuity, and payment method. J Gen Intern Med. 1998;13:681-6.

16. Douglas BC, Noble LM, Newman SP. Improving the accuracy of patients' expectations of the psychiatric out-patient consultation. Psy Bull. 1999;23:425-7.

17. Rubin HR, Gandek B, Rogers WH, Kosinski M, McHorney CA, Ware JE Jr. Patients' ratings of outpatient visits in different practice settings. Results from the Medical Outcomes Study. JAMA. 1993;270(7):835-40.

18. Morisky DE, Green LW, Levine DM. Concurrent and predictive validity of a self-reported measure of medication adherence. Med Care. 1986;24:67-74.

19. Vinayak N. From doctor to social doctor. In: Madhok R, editor. Promoting Professionalism and Ethical Practices in Medicine: Indian doctors from across the globe working together. A publication of global association of physicians of Indian origin (GAPIO); 2014. p. 15-7.

20. Furnham A. Psychiatric and psychotherapeutic literacy: attitudes to, and knowledge of, psychotherapy. Int J Soc Psychiatry. 2009;55(6):52537.

21. Aloud N, Rathur A. Mental health and psychological services among Arab Muslim populations. J Muslim Ment Health. 2009;4:79-103.

22. Fox JG, Storms DM. A different approach to sociodemographic predictors of satisfaction with health care. Soc Sci Med A. 1981;15(5):557-64.

23. Linder-Pelz SU. Toward a theory of patient satisfaction. Soc Sci Med. 1982;16(5):577-82.

24. Ware JE Jr, Snyder MK, Wright WR, Davies AR. Defining and measuring patient satisfaction with medical care. Eval Program Plann. 1983;6(34):247-63.

25. Donabedian A. Explorations in Quality Assessment and Monitoring. Vol. 1. The Definition of Quality and Approaches to Its Assessment. Ann Arbor, MI: Health Administration Press; 1980.
26. Mancuso CA, Graziano S, Briskie LM, Peterson MG, Pellicci PM, Salvati EA, et al. Randomized trials to modify patients' preoperative expectations of hip and knee arthroplasties. Clin Orthop Relat Res. 2008;466(2):424-31.

27. Gandhi R, Davey JR, Mahomed N. Patient expectations predict greater pain relief with joint arthroplasty. J Arthroplasty. 2009;24(5):716-21.

28. Junod Perron N, Secretan F, Vannotti M, Pecoud A, Favrat B. Patient expectations at a multicultural out-patient clinic in Switzerland. Family Practice. 2003;20:428-33.

29. Doney PM, Cannon JP. An examination of the nature of trust in buyer-seller relationships. J Marketing. 1997;61(2):35-51.

30. Fugelli P. Trust-in general practice. Br J Gen Pract. 2001;51(468):575-9.

31. Rascol O, Hauser R, Stocchi F, Ha X, Capece R, Wolski K, et al. Post-hoc analyses of phase- 3 data with preladenant, an adenosine $2 \mathrm{a}$ antagonist, in patients with Parkinson's disease. Neurology. 2014;82(10):7.

32. Toonstra JL. The Relationship between Patient Expectations, Functional Outcome, Self efficacy, and Rehabilitation Adherence Following Cartilage Repair of the Knee: A Sequential Explanatory Analysis. 2014. Theses and Dissertations--Rehabilitation Sciences. Paper 20. Available at: http:// uknowledge.uky.edu/rehabsci_etds/20. Assessed on: Jun 20, 2014.

33. Deci EL. Why We Do What We Do: Understanding Self-Motivation. London: Penguin; 1995.

34. Kassis IT, Ghuloum S, Mousa H, Bener A. Treatment non-compliance of psychiatric patients and associated factors: are patients satisfied from their psychiatrist? B J Med Res. 2013;4(2):16-31.

35. Pareek B, Kalia R. Factors affecting non-compliance to psychotropic drugs of patients with psychosis as perceived by their family members attending the psychiatric outpatient department at selected hospital, Mangalore. Nurs Midwifery Res J. 2013;9(2):56-62.

36. Shah PS. Trend of psychiatric disorders among out-patients and in-patients of a tertiary care center of India. Int J Res Med Sci. 2014;2(2):439-44.

37. Ganguli HC. Epidemiological findings on prevalence of mental disorders in India. Indian J Psychiatry. 2000;42(1):14-20. 